\title{
Ameliorative Effects of Aqueous Extract of Date Palm Fruits (phoenix dactylifera) on high fat diet- induced Liver Damage in Adult Wistar Rats
}

\author{
*1 ONYILO, PO; ${ }^{2}$ INNIH, SO, ${ }^{2}$ IHEMESON, G; ${ }^{2}$ OGEREKA, LU; ${ }^{2}$ NWEKE, SM, \\ ${ }^{2}$ OBELE, EI; ${ }^{2}$ NWALIE, IN
}

\begin{abstract}
${ }^{*}$ Department of Anatomy, Faculty of Basic Medical Sciences, College of Health Sciences, Delta State University, Abraka, Nigeria. ${ }^{2}$ Department of Anatomy, School of Basic Medical Sciences, College of Medical Sciences, University of Benin, Benin-city, Nigeria. *Corresponding Author Email: peaceewoma@gmail.com
\end{abstract}

\begin{abstract}
Elevated cholesterol level is a major cause of disease burden in developing Nations. This study seeks to evaluate the ameliorative and hepatoprotective potentials of aqueous extract of date palm (Phoenix dactylifera) on high fat diet-induced liver damage. Thirty (30) adult wistar rats weighing 110-180g were randomly divided into six group of five animals each, group A served as control while B was exposed to high fat diet only (using margarine brand); Groups $\mathrm{C}, \mathrm{D}$ and $\mathrm{E}$ were given high fat diet with co-treated with the extract at low, medium and high doses respectively while group $\mathrm{F}$ was received the drug Atrovastin as a gold standard to enable comparative effects of date palm administration. At the end of the treatment period, the animals were anaesthetized using chloroform blood samples were collected via cardiac puncture to investigate the activities of liver enzymes, and liver tissue was harvested through a midline incision for histological analysis. There were evidence of vascular congestion and periportal infiltration in rats given margarine only indicative of hepatocellular disruption. Animals that received moderate to high dose of the fruit extract show mild to total reversal of the damaged liver cells and activation of kupffer cells with concurrent changes in serum albumin level. Aqueous extract of phoenix dactylifera was seen to ameliorate the fat induced liver damage with notable changes in hepatocyte configuration as observed when treated with standard drug.
\end{abstract}

\section{DOI: https://dx.doi.org/10.4314/jasem.v25i3.4}

Copyright: Copyright (C) 2021 Onyilo et al. This is an open access article distributed under the Creative Commons Attribution License (CCL), which permits unrestricted use, distribution, and reproduction in any medium, provided the original work is properly cited.

Dates: Received: 12 December 2020; Revised: 26 January 2021; Accepted: 12 February 2021

Keywords: Phoenix dactylifera, Hyperlipedermia, Liver, Wistar rat

Hyperlipidemia is a medical condition characterized by increased serum level of the plasma lipids, including triglycerides, cholesterol, cholesterol esters, phospholipids and low-density lipoprotein (Amarenco and Labrenche, 2009). Saturated fatty acids in regular diet is a notable risk factor for elevated lipid level which could result in cardiovascular diseases and promote inflammation (Bellosta et al., 2004). Globally, one third of ischemic heart disease accounting for 2.6million deaths and 29.7 million disabilities are attributable to high cholesterol as reported by World Health Organization. More so hyperlipidemia has been detected as a modifiable risk factor for atherosclerosis and related cardiovascular diseases notably coronary heart disease, cerebral stroke, myocardial infarction and renal failure (Ginghina et al., 2011).

The liver removes Low Density Lipoproteins (LDL) from the circulation by receptor-mediated endocytosis. (Hegele 2009). The link between cholesterol and heart disease was recognized through the study of individuals with familial hypercholesterolemia (Carlson, 2005). A lipid profile typically measures total cholesterol level, LDL and HDL cholesterol; Cholesterol is mainly synthesized in the liver and the total level in the body is highly dependent on diet, nutritional values and (Mishra et al., 2011).

Therapeutic models for hyperlipidemia is dependent on decreasing blood lipid level; synthetic drugs that lower cholesterol level in the body notably statins, fibrates and nicotinic acid, are expensive and may exhibit undesirable effect (Horie et al., 1991; Xiaoqing et al., 2012). Several drugs are used to decrease LDL cholesterol such as "statin" (HMG-CoA reductase inhibitor), bile acid sequestrates, nicotinic acid and gemfibrozil. Statin lowers cholesterol by interfering with the cholesterol biosynthetic pathways (Eiland and Lutrell, 2010) while fibrates decrease fatty acid and triglyceride levels by stimulating the peroxisomal $\beta$-oxidation pathway (Mills et al., 2011). Hyperlipidemic treatment has shown measurable successful outcomes in long term treatments; however other avenues for possible solution are still 
inadequately investigated specifically the application of herbal remedies. Consumption of local herbs and plants contributes significantly to general well-being and improvement of health, in terms of prevention and management of certain disease conditions. Plants remain a viable natural source of the therapeutic agents. About eighty percent of the world populace relies on traditional medicine for their primary health needs, and today plant-based drugs are primal to quality health care (Diab and Abdoul-ela, 2012). Date palm is rich in fibers with adequate nutritional qualities, is a widely distributed crop in tropical region.

The seed and fruit is highly valued for its remedial potentials in managing symptoms associated with lower respiratory tract infection, common cold, and other terminal ailments like cancer. Essential minerals such as calcium, iron, sodium and rich in phytochemicals like tannins. It is rich in antiinflammatory properties that tends to reduce high cholesterol regions level associated with various inflammatory and deteriorating activities in tissues and organs (Kruger and Robert, 2018; Walid et al., 2003). This study evaluated ameliorative potentials of aqueous extract of phoenix dactylifera fruits on high fat diet-induced liver damage in adult wistar rats and to justify the possible use of date palm as an alternative form of treatment in the management of liver dysfunction induced by high cholesterol diet.

\section{MATERIALS AND METHODS}

Collection and Preparation of Date fruits Extract: Date fruits were procured from local traders in New Benin market, Benin City, Edo State. They were identified and authenticated in the Department of Plant biology and biotechnology. Faculty of Science, University of Benin. The fruits were then washed pulverized and stored in a cool dry place. The powdered extract was soaked for about 48 hours at room temperature. The mixture was filtered into a conical flask with watman filter paper. The filtrate was then dried $40^{\circ} \mathrm{c}$ for 10 hours to produce a gel-like extract. Appropriate concentrations of the extract were then subsequently made by dilution with water. All preparations were done at the Department of Pharmacognosy, Faculty of Pharmacy, University of Benin.

Animals care and Housing: Thirty (30) adult Wistar rat weighing $110-180 \mathrm{~g}$ were purchased and kept in plastic cages in the animal House of the Department of Anatomy, University of Benin. The animals were given access to standard rat chow and water and allowed to acclimatize for two weeks under standard conditions prior to the beginning of the experiment.
Experimental Design: Thirty animals weighing between 110 - $180 \mathrm{~g}$ were assigned to six groups comprising five rats each. Group A was designed as the control and were given access to animal feed and water ad libitum. Group B received $3 \mathrm{~g} / \mathrm{kg}$ per body weight of margarine-oil mixture daily throughout the treatment period. Group $\mathrm{C}$ were given margarine-oil and low dose of the fruit extract $(200 \mathrm{mg} / \mathrm{kg})$. Group D animals received margarine-oil mixture and $400 \mathrm{mg} / \mathrm{kg} /$ day (moderate dose) of date palm extract Group E received margarine-oil mixture, and $800 \mathrm{mg} / \mathrm{kg} /$ day (high dose) of extract for 8 weeks. Group F: received margarine-oil mixture was With standard drug, Atorvastatin (as a model to compare findings from the fruit extract).

Animal Sacrifice and collection of sample: At the end of the treatment period, animals from each group were anaesthetized using chloroform.

A midline abdominal incision was made, blood samples were collected from the abdominal aorta and kept in heparinized bottles for evaluation of liver function via assay of the following enzymes Serum Alanine amino Transferase (ALT), Serum Aspartate amino Transferase (AST), Alkaline Phosphatase (ALP), Total Protein (TP), albumin, globulin, total bilirubin13. However, the liver tissue was harvested, fixed in formal saline and processed following standard histological technique to evaluate for morphological changes.

Histological Analysis: The Liver was excised, fixed in $10 \%$ formal saline solution and processed via routine histological procedure. The tissues were dehydrated by passing them through ascending grade of alcohol (70\%, 90\% and 100\%) and processed following standard procedure as recommended by Drury and Wallington 1980.

Statistical Analysis: Data generated were analyzed using simple descriptive statistics expressed as (mean+/ SEM) and 1were subjected to one way analysis of variance (ANOVA) using SPSS. Individual comparison were obtained by the Duncan multiple range test $(\mathrm{DMRT})$. A value of $\mathrm{p}<0.05$ indicates a significant difference between groups (Duncan, 1957).

\section{RESULTS AND DISCUSSION}

There were no significant differences in the liver enzymes across treatment groups when compared to control except with Albumin which showed considerable changes especially in Group D, E and F (Table 1). 
Table 1. Liver function test in wistar rats after the administration of margarine, aqueous extracts of phoenix dactylifera and atorvastatin

\begin{tabular}{|c|c|c|c|c|c|c|}
\hline Parameter & $\begin{array}{l}\text { Control } \\
\text { Group A }\end{array}$ & $\begin{array}{l}\text { Margarine } \\
\text { Only } \\
(3000 \mathrm{mg} / \mathrm{kg}) \\
\text { Group B } \\
\end{array}$ & $\begin{array}{l}\text { Low Dose Extract } \\
(200 \mathrm{mg} / \mathrm{kg})+ \\
\text { Margarine } \\
\text { Group C }\end{array}$ & $\begin{array}{l}\text { Medium Dose } \\
(400 \mathrm{mg} / \mathrm{kg})+ \\
\text { Margarine } \\
\text { Group D }\end{array}$ & $\begin{array}{l}\text { High Dose } \\
(800 \mathrm{mg} / \mathrm{kg}) \\
+ \text { Margarine } \\
\text { Group E }\end{array}$ & $\begin{array}{l}\text { Atorvastatin } \\
(0.3 \mathrm{mg} / \mathrm{Kg}) \\
+ \text { Margarine } \\
\text { Group F } \\
\end{array}$ \\
\hline \multirow{2}{*}{$\begin{array}{l}\text { Alanine } \\
\text { aminotransferase }\end{array}$} & 28.83 & 22.13 & 21.00 & 28.19 & 19.21 & 20.11 \\
\hline & \pm 2.80 & ${ }^{ \pm} 4.16$ & ${ }^{ \pm} 4.38$ & \pm 3.45 & \pm 2.86 & \pm 3.99 \\
\hline \multirow{2}{*}{$\begin{array}{l}\text { Aspartate } \\
\text { aminotransferase }\end{array}$} & 35.20 & 34.17 & 30.30 & 37.59 & 28.22 & 32.35 \\
\hline & \pm 3.08 & \pm 5.62 & \pm 3.98 & ${ }^{ \pm} 6.67$ & ${ }^{ \pm} 1.68$ & \pm 4.87 \\
\hline \multirow{2}{*}{$\begin{array}{l}\text { Alkaline } \\
\text { phosphatase }\end{array}$} & 102.7 & 79.42 & 93.95 & 110.8 & 90.94 & 86.65 \\
\hline & ${ }^{ \pm} 13.18$ & ${ }^{ \pm} 10.12$ & ${ }^{ \pm} 16.65$ & ${ }^{ \pm} 13.03$ & ${ }^{ \pm} 9.39$ & ${ }^{ \pm} 9.03$ \\
\hline \multirow[t]{2}{*}{ Albumin } & 2.758 & 3.715 & 3.227 & 3.615 & 4.554 & 4.715 \\
\hline & ${ }^{ \pm} 0.31$ & ${ }^{ \pm} 0.61$ & ${ }^{ \pm} 0.86$ & ${ }^{ \pm} 0.84$ & ${ }^{ \pm} 0.43^{*}$ & ${ }^{ \pm} 0.31$ * \\
\hline \multirow[t]{2}{*}{ Total protein } & 3.094 & 3.638 & 3.940 & 2.515 & 4.384 & 4.958 \\
\hline & ${ }^{ \pm} 0.20$ & ${ }^{ \pm} 0.44$ & ${ }^{ \pm} 0.63$ & ${ }^{ \pm} 0.31$ & ${ }^{ \pm} 0.35^{*}$ & ${ }^{ \pm} 1.04 *$ \\
\hline \multirow[t]{2}{*}{ D.Bilirubin } & 0.26 & 0.49 & 0.31 & 0.49 & 0.37 & 0.36 \\
\hline & ${ }^{ \pm} 0.05$ & ${ }^{ \pm} 0.20$ & ${ }^{ \pm} 0.12$ & ${ }^{ \pm} 0.17$ & ${ }^{ \pm} 0.06$ & ${ }^{ \pm} 0.04$ \\
\hline \multirow[t]{2}{*}{ Total Bilirubin } & 0.29 & 0.36 & 0.32 & 0.38 & 0.27 & 0.32 \\
\hline & ${ }^{ \pm} 0.03$ & ${ }^{ \pm} 0.07$ & ${ }^{ \pm} 0.04$ & ${ }^{ \pm} 0.12$ & ${ }^{ \pm} 0.02$ & ${ }^{ \pm 0} 0.04$ \\
\hline
\end{tabular}

$* P<0.05$ indicates significant difference in treated groups compared with the control group.

Photomicrographs (Plates 1 to 6) showed evidence of vascular congestion and periportal infiltration in Group B animals given margarine only while group treated with date palm extract revealed mild changes at low dose (Group C) and complete reversal to normal liver architecture at moderate to high doses (Group D and E) indicating that the extract's effect is dose dependent. However animals treated with standard drug in Group F showed complete ameliorative changes comparable to those given date palm extract.

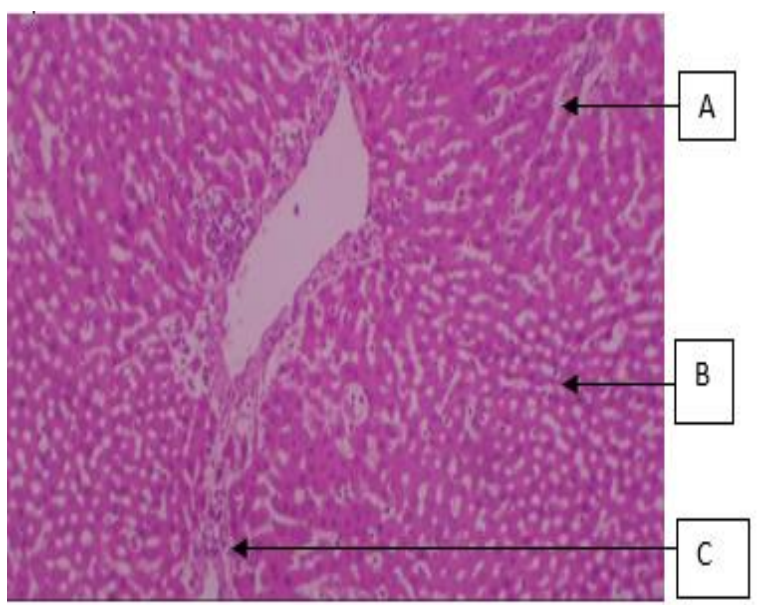

Plate 1: Group A; Control. A, hepatocytes, B, sinusoids, C, portal vein, D, central vein $(H \& E \times 100$

High fat diet has been under scrutiny because it is considered as one of the causes of hyperlipidemia (the secondary class). Hyperlipidemia in turn have been associated with several health challenges like ischemia, chronic heart disease and stroke. Phoenix dactylifera fruits exhibit ameliorative antiinflammatory, anti-oxidative and antitumor properties (Rahmani et al., 2014). Histoarchitectural evaluation of the liver in the control group showed normal hepatocyte configuration with kupffer cells activation at moderate to high doses of the extract. However, there was evidence of vascular congestion and periportal infiltrates of inflammatory cells which are characteristics of portal hepatitis observed in the group restricted to fatty diet only.

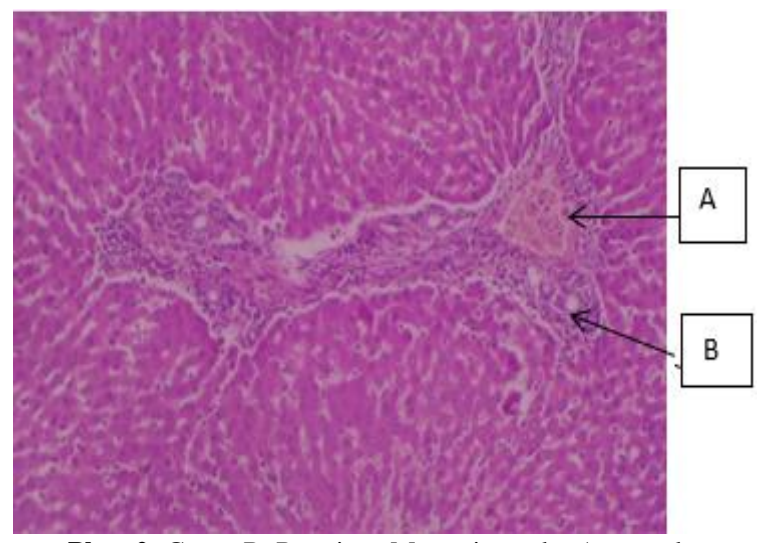

Plate 2: Group B; Rat given Margarine only: A, vascular congestion and $\mathrm{B}$, periportal infiltrates of inflammation $(\mathrm{H} \& \mathrm{E} \mathrm{x}$ 100).

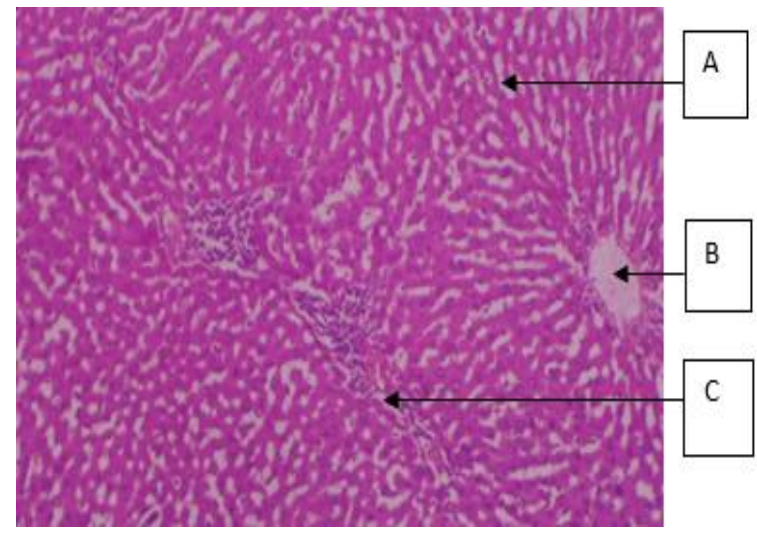

Plate 3: Group C; Rat given Margarine plus low dose of Extract: $\mathrm{A}$, normal hepatocytes $\mathrm{B}$, vasculature, duct and $\mathrm{C}$, mild inflammation (H\&E x 100) 


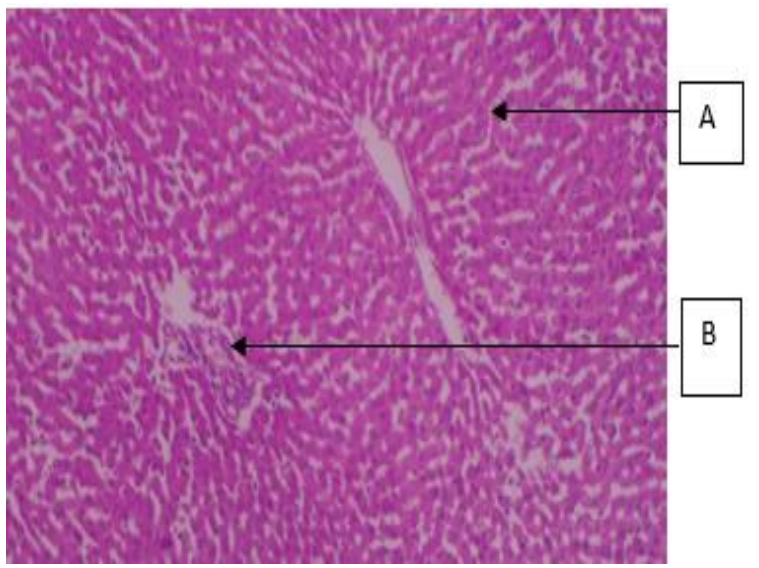

Plate 4: Group D; Rat given Margarine plus moderate dose Extract: A, normal hepatocytes and B, Kupffer cell activation $(\mathrm{H} \& \mathrm{E} \times 100)$

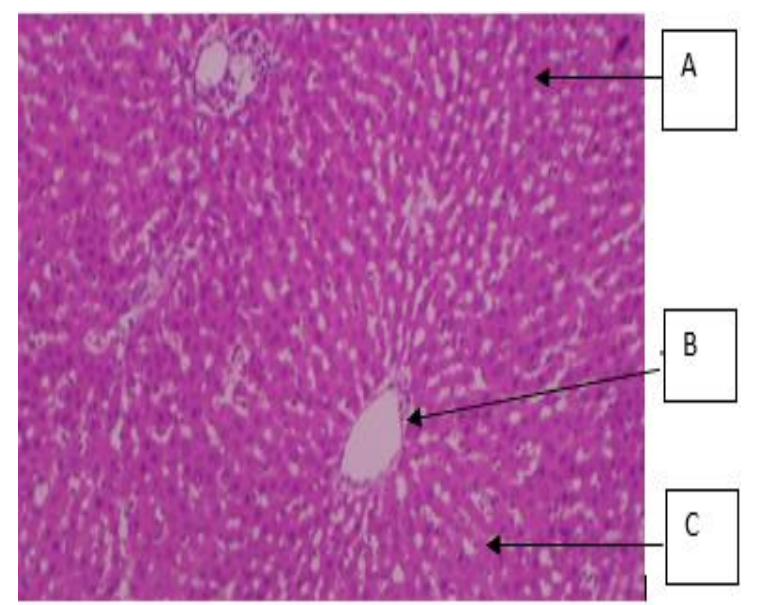

Plate 5: Group E; Rat given Margarine plus high dose Extract: A, normal hepatocytes $\mathrm{B}$, vasculature and $\mathrm{C}$, Kupffer activation $(\mathrm{H} \& \mathrm{E}$ $\mathrm{x}$ 100)

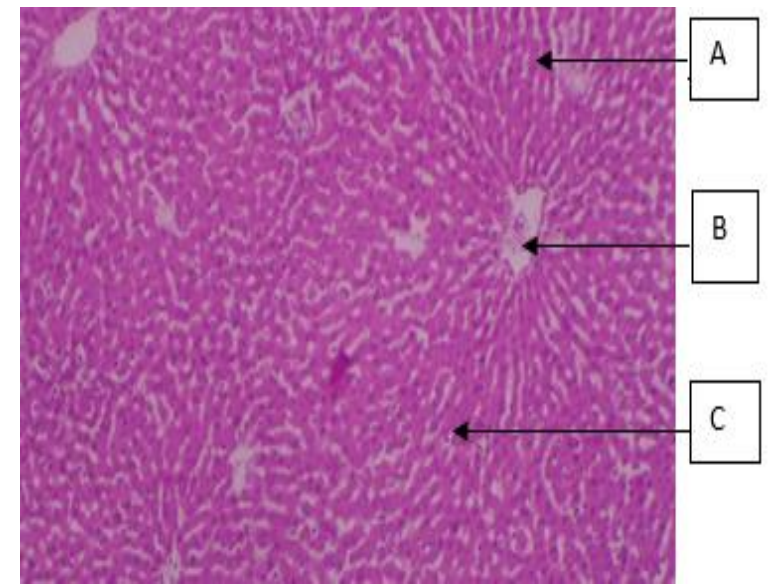

Plate 6: Group F; Rat given Margarine plus Standard drug: A, normal hepatocytes B, vasculature and C, Kupffer cell activation (H\&E x 100)

This is consistent with finding from similar investigation showing the high degree of hepatic damage attributable to certain diet type and lead pollution (El- Sokkary et al.,2005).Treatment of induced animals with phoenix dactylifera extract at low dose, show evidence of mild periportal infiltrates of inflammatory cells suggesting gradual reversal of the hepatic damage, at medium to high dosage, there was complete amelioration evident through kupffer cells activation and presence of normal hepatocyte consistent with normal cellular features seen when given standard drug Atrovastin. Biochemical markers analyzed through the liver function test revealed an increase in albumin and total protein level in the group treated with high doses of the extract as well as those given atorvastatin. However no statistically significant difference $(p>0.05)$ in Alanine aminotransferase, Aspartate transaminase, Alkaline phosphatase and bilirubin levels in the treated groups as compared to control. This finding is harmonious with previous work on ameliorative potentials of date Palm on the distorted hepatocytes which revealed no significant difference $(p>0.05)$ in the level of bilirubin compared to the control (Adachi et al., 1995). Albumin is an essential body protein, soluble in water and has various important functions. Decrease in albumin level shows evidence of disease conditions in the liver (Zawn, 2018). Therefore increased level of albumin in the groups treated with the extract further confirms the hepatoprotective potentials of date palm similar to the results achieved with standard drug Atorvastatin.

Conclusion: It was evident that phoenix dactylifera could ameliorate the destructive effects of fat based diet on the liver attributable to its anti- inflammatory, anti-oxidant and anti-tumor properties. The extract had appreciable effects on liver functions via its hepatoprotective activities.

Acknowledgement: The authors wish to thank all Staff of Anatomy Department, University of Benin for their kind support. There was no external source of funding for this research.

\section{REFERENCES}

Adachi, Y; Moore, LE; Bradford, BU; Gao, W; Thurman, RG (1995). Antibiotics prevent liver injury in rats following long-term exposure to ethanol. Gastroent. 8(1), 218-224.

Amarenco, P; Labreuche, J (2009). Lipid management in the prevention of stroke: review and updated meta-analysis of statins for stroke prevention. Lancet Neurol. 8 (5): 453 - 463.

Bellosta, S; Paoletti, R; Corsini, A (2004). Atherosclerosis: Evolving vascular biology and clinical implications, safety of statins: focus on 
clinical pharmacokinetics and drug interactions. Circulation. 109: 50-57.

Carlson, LA (2005). Nicotinic acid: the broadspectrum lipid drug. A 50th anniversary review. $J$. Intern. Med. 258 (2):94-114.

Drury, EA; Wallington, EA (1980). Carleton's histological technique. Oxford university press. $5^{\text {th }}$ edition.

Diab, KA; Aboul-Ela, EI (2012). "In Vivo Comparative Studies on Antigenotoxicity of Date Palm (Phoenix Dactylifera L.) Extract against DNA Damage Induced by N-Nitroso-Nmethylurea in Mice". Diab. Vascul. Dis. Resume. 3(2): 93-102.

Eiland, LS; Luttrell, PL (2010). Use of statins for dyslipidemia in the pediatric population. $J$. Pediatr. Pharmacol. Therap. 15(3): 160-172.

El-sokkary, GH; Abdel-Rahman, GH; Kamel, ES (2005). Melatonin protects against lead-induced hepatic and renal toxicity in male rats. 213: 25-33.

Ginghina, C; Bejan, I; Ceck, CD (2011). Modern risk stratification in coronary heart disease. J. Med. Life. 4 (4): 377-86.

Hegele, AR (2009). Plasma lipoproteins: genetic influences and clinical implications. Nat. Rev. Genet. 10: 109-121.

Horie, M; Sawasaki, Y; Fukuzumi, H; Watanable, K; Lizuka, Y; Tsuchiya, Y; Kamei, T (1991). Hypolipidemic effects of NB-598 in dogs. Atheroscler. 88(2-3): 183-192.

Krueger, RR (2018). "Date Palm Genetic Resource Conservation, Breeding, Genetics, And Genomics In California" The Conference Exchange Retrieved.
Mills, EJ; Wu, P; Chong, G; Ghement, I; Singh, S; Eyawo, O; Guyatt, G; Berwanger, O; Briel, M (2011). Efficacy and safety of statin treatment for cardiovascular disease: a network meta-analysis of 170,255 patients from 76 randomized trials. QJM. 104 (2):109-124.

Mishra, PR; Panda, PK; Apanna, KC; Panigrahi, S (2011). Evaluation of acute hypolipidemic activity of different plant extracts in Triton WR-1339 induced hyperlipidemia in albino rats. Pharmacol. online. 3: 925-934.

Rahmani, H; Aly, SM; Ali, H; Babiker, AY; Suikar, S; Khan, AA (2014). "Therapeutic effects of date fruits (Phoenix dactylifera) in the prevention of diseases via modulation of anti-inflammatory, antioxidant and anti-tumour activity," Int. J. Clin. Exp. Med. 7 (3): 483-491.

Walid, A; Marshall, RJ (2003). "The fruit of the date palm: its possible use as the best food for the future? Int. J. Food Sci. Nutri. 54 (4): 247-259.

Xiao-Qing Lian , XQ; Wang, YS; Zhu, J; Jian-Jun Yan, JJ; Zhang, DG; Zhi-Jian Yang, ZJ; Wang, LS (2012). Plasma levels of lipid metabolismrelated miR-122 and miR-370 are increased in patients with hyperlipidemia and associated with coronary artery disease. Lipids Health Dis. (11): 55.

Zawn, V (2018). Medical News Today. "What are the effects of low albumin". Revised by Elaine K. Luo MD.

www.medicalnewstoday.com/articles/321149. 